\title{
To the Question of Structure Formation of Dispersed Systems in Cement Technology
}

\author{
Chernyak Lev, Sviderskyy Valentin, Tokarchuk Volodymyr, Dorogan Natalia \\ Department of Chemical Technology of Composite Material, National Technical University of Ukraine "Igor Sikorsky Kyiv Polytechnic \\ Institute", Kyiv, Ukraine
}

Email address:

lpchernyak@ukr.net (C.Lev),xtkm@kpi.ua (S. Valentsn), tokarchuk.volodya@yandex.ua (T. Volodymyr), nataliyadorogan@ukr.net (D. Natalia)

\section{To cite this article:}

Chernyak Lev., Sviderskyy Valentin., Tokarchuk Volodymyr., Dorogan Natalia. To the Question of Structure Formation of Dispersed Systems in Cement Technology. World Journal of Applied Chemistry. Vol. 5, No. 3, 2020, pp. 41-46. doi: 10.11648/j.wjac.20200503.11

Received: July 10, 2020; Accepted: July 24, 2020; Published: August 10, 2020

\begin{abstract}
In the this publication, readers will find the results of the analytical and experimental research into the physical and chemical processes in the consecutive formation of structures at the major technological stages of the present-day production of portland cement. Dispersed systems of raw mixtures, which in different methods of production are formed at the stage of grinding, mixing and homogenization of raw materials, belong to different classification groups. In wet and combined methods is produced cement sludge - aqueous dispersed system, which belongs to the 2nd group: two-phase systems such as solid dispersed phase - liquid dispersion medium. In the dry method dispersed system is formed, which belongs to the 3rd group: three-phase systems such as solid dispersed phase - water-liquid and air-gas dispersion medium. The structuralmechanical and rheological properties of the coagulation structure of cement slurries, wich differ in the main raw material components, are shown. The study of deformation processes of aqueous dispersed systems showed that the nature of the development of deformations - rapid elastic $\varepsilon_{0}$ ', slow elastic $\varepsilon_{2}$ ' and plastic $\varepsilon_{1}{ }^{\prime} \tau$ sludge samples belong to different structural mechanical types. At the same time differences in quantitative values and a ratio of the specified types of deformation are noted. Readers will also find the particularities of the phase changes in the process of the crystallization structure formation at baking to maximum temperature $1450^{\circ} \mathrm{C}$.
\end{abstract}

Keywords: Cement, Technology, Structure, Water System, Baking, Phase Composition

\section{Introduction}

The technology of cement production is developing in the direction of expanding the raw material base with the involvement of waste from other industries as man-made raw materials, mechanization and increasing the productivity of equipment, reducing specific energy consumption during firing and grinding [1-3]. The urgency of these tasks is enhanced in modern conditions, when ensuring the competitiveness of the cement industry requires increased production efficiency, addressing resource conservation and ecology on an innovative basis. This necessitates the development of physico-chemical bases of binder technology, based on the concept of the relationship "composition structure - properties".

\section{Structural Formation in Modern Methods of Cemzent Production}

According to the provisions of physico-chemical mechanics, the technological process of production of silicate materials is essentially a process of formation and successive transformations of their structure [4-6]. There are three main types of structure: coagulation, condensation and crystallization. Therefore, in order to effectively regulate the properties and improve the quality of silicate materials, including cement, it is necessary to comprehensively consider the processes of structure formation and production technology.

In modern cement production, wet, combined and dry methods are used, which, with certain differences in the 
parameters of the processes of technology and structure formation, must provide equally high specified product properties.

The properties of cement are closely related to the raw material, production parameters, the composition of the clinker, the degree of its dispersion and additives in grinding.

Dispersed systems of raw mixtures, which in these methods of production are formed at the stage of grinding, grinding, mixing and homogenization of raw materials, belong to different classification groups [7]. In wet and combined methods due to grinding, mixing, homogenization of a mixture of raw materials with water is produced cement sludge - aqueous dispersed system, which belongs to the 2nd group: two-phase systems such as solid dispersed phase liquid dispersion medium. In the dry method due to grinding, mixing, drying of the mixture of raw materials, a dispersed system is formed, which belongs to the 3rd group: threephase systems such as solid dispersed phase - water-liquid and air-gas dispersion medium.

The coagulation structure of raw mixtures is determined by surface properties and hydrophilicity, chemical and mineralogical composition, dispersion and concentration of particles of the dispersed phase. The latter increases significantly in mixtures during the transition from wet to combined and dry production methods.

Features of formation of coagulation structure of cement sludge in technological process are defined by stages: interaction of a surface of particles of components of a dispersed phase with the water dispersion environment $\rightarrow$ change of chemical-mineralogical and granulometric structures at joint grinding of carbonate and clay components and mineral additives $\rightarrow$ partial destruction and change of external characteristics. during transportation $\rightarrow$ increase in concentration of a dispersed phase at partial (by the combined method) ab intense (if wet) dehydration in the rotary kiln.

The process of formation of coagulation-condensation and condensation structures in the modern technology of Portland cement takes place at the stages of manufacturing the raw material mixture by combined and dry production methods. In the wet production method, the stage of condensation structure formation is minimized in time and actually gives way to the processes of phase transformations and the formation of the crystallization structure of clinker during firing.

The crystallization structure of Portland cement clinker is characterized by the type, quantity, degree of morphological perfection of crystalline formations, glass phase composition, quantitative ratio of crystalline and glass phases. The formation of the crystallization structure of clinker takes place during heat treatment of the raw mixture at the stages of decarbonization and destruction of crystal lattices of rock-forming minerals of dispersed particles, solid-phase reactions of physicochemical interaction of destruction products, formation of liquid phase, sintering in the presence of liquid phase [8-15]. It is obvious that in such a sintering process the silicate system can be determined by the presence of a coagulation structure of the second kind and can also be referred to the 2nd group: two-phase systems such as solid dispersed phase - liquid dispersion medium (melt). The chemical and mineralogical composition of the mixture, the method of its preparation and the parameters of high-temperature processing - firing - are determining factors in achieving a given mineralogical composition of clinker.

The final properties of the cement are achieved at the stage of fine co-grinding of clinker with mineral additives, resulting in a sharp increase in the degree of defect, effective specific surface area and reactivity of the binder. The dispersed system belongs to the 1st group: two-phase systems of the solid dispersed phase type - gas-air dispersion medium.

\section{The Experimental Part}

The coagulation structure of the sludge of the raw material mixture can be characterized by indicators of structuralmechanical, rheological and technological properties. In the presented work the comparison of sludges of raw mixtures $\mathrm{Np}$ and $\mathrm{Zd}$ used in the wet production of gray Portland cement at PJSC "YuGcement" and PJSC "Volyn-Cement" was carried out.

The studied mixtures differ in the main raw material components: $\mathrm{Np}$ is made on the basis of the system of limestone - polymineral clay, Zd -. based on the system of chalk - polymineral clay, the mineralogical composition of the sample $\mathrm{Zd}$ differs from $\mathrm{Np}$ with a higher content of calcite, kaolinite and hydromica.

The study of deformation processes of aqueous dispersed systems showed (Tables 1-3) that the nature of the development of deformations - rapid elastic $\varepsilon_{0}$ ', slow elastic $\varepsilon_{2}$ ' and plastic $\varepsilon_{1}$ ' $\tau$ sludge samples belong to different structural - mechanical types: $\mathrm{Np}$ - to type IV, when $\varepsilon_{1}$ ' $\tau>$ $\varepsilon_{0}{ }^{\prime}>\varepsilon_{2}, \mathrm{Zd}-$ to type $\mathrm{V}$, when $\varepsilon_{1}{ }^{\prime} \tau>\varepsilon_{2}{ }^{\prime}>\varepsilon_{0}$ '. At the same time differences in quantitative values and a ratio of the specified types of deformation are noted.

Thus, at an equal concentration of the dispersed phase, the slurry $\mathrm{Zd}$ differs from $\mathrm{Np}$ by a greater development of $\varepsilon_{2}$ ', which is $3.57 \cdot 10^{8}$ against $0.16 \cdot 10^{8}$, a much greater development of $\varepsilon_{1}$ ' $\tau-66.66 \cdot 10^{8}$ against $7.02 \cdot 10^{8}$. That is, according to the ideas of physical and mechanical mechanics of dispersed structures, in accordance with the numbers $\varepsilon 2$ 'sludge $\mathrm{Zd}$ compared to $\mathrm{Np}$ when using chalk instead of limestone is characterized by greater development of contacts of particles such as plane-angle, plane-edge, plane-plane. 
Table 1. Structural and mechanical characteristics of cement sludge.

\begin{tabular}{|c|c|c|c|c|c|c|c|c|}
\hline $\begin{array}{l}\text { Mixture code } \\
\text { (humidity, } \\
\text { wt.\%) }\end{array}$ & $\begin{array}{l}\text { module of fast } \\
\text { elastic } \\
\text { deformation } \\
\mathbf{E}_{1} \cdot 10^{-4}, \mathrm{~Pa}\end{array}$ & $\begin{array}{l}\text { modulus of slow } \\
\text { elastic } \\
\text { deformation } \\
\mathrm{E}_{2} \cdot 10^{-4}, \mathrm{~Pa}\end{array}$ & $\begin{array}{l}\text { conditional } \\
\text { static yield } \\
\text { strength } P_{k 1} \text {, } \\
\text { Pa }\end{array}$ & $\begin{array}{l}\text { greatest plastic } \\
\text { viscosity } \eta_{1} \cdot 10^{-2}, \\
\text { Pa.c }\end{array}$ & $\begin{array}{l}\text { elasti-city } \\
\lambda\end{array}$ & $\begin{array}{l}\text { static plasticity } \\
\frac{P_{k 1}}{\eta_{1}} \cdot 10^{2} \mathrm{c}^{-1}\end{array}$ & $\begin{array}{l}\text { period of } \\
\text { true } \\
\text { relaxation } \theta_{1} \text {, } \\
\text { c }\end{array}$ & $\begin{array}{l}\text { conditional } \\
\text { modulus of } \\
\text { deformation } \\
\mathbf{E}_{\varepsilon} \cdot \mathbf{1 0}^{-10}, \mathrm{~J} / \mathrm{cm}^{3}\end{array}$ \\
\hline $\mathrm{N}_{\mathrm{l}}$ & 32,6 & 125,4 & 1,40 & 28 & 0,21 & 4,9 & 110,6 & 2,57 \\
\hline $\mathrm{Zd}(37,6)$ & 18,74 & 5,60 & 2,63 & 3,00 & 0,77 & 0,88 & 70 & 0,28 \\
\hline
\end{tabular}

The predominant development of plastic deformations $\varepsilon 1$ ' $\tau$ indicates an increase in the flowability of sludge samples. The kinetic stability, which is determined by the coefficient $\mathrm{K}_{\mathrm{y}}=\varepsilon_{0}$ ' / $\mathrm{C}$ (where $\mathrm{C}$ is the concentration of the dispersed phase), in the case of sludge $\mathrm{Zd}$ is less -0.02 against 0.12 .

Table 2. Development of deformations in cement sludge samples.

\begin{tabular}{|c|c|c|c|c|c|}
\hline \multirow{2}{*}{ Mixture code } & \multicolumn{3}{|l|}{ Types of deformation } & \multirow{2}{*}{$\begin{array}{l}\text { Coefficient stability } \\
\varepsilon_{0} / \mathrm{C}\end{array}$} & \multirow{2}{*}{$\begin{array}{l}\text { Structurally-mechanical } \\
\text { type }\end{array}$} \\
\hline & rapid elastic $\varepsilon_{0}, 10^{8}$ & slow elastic $\varepsilon_{2}{ }^{\prime} \cdot 10^{8}$ & plastic $\varepsilon_{1}{ }^{\prime} \tau \cdot 10^{8}$ & & \\
\hline $\mathrm{Np}$ & 0,61 & 0,16 & 7,02 & 0,12 & IV \\
\hline $\mathrm{Zd}$ & 1,07 & 3,57 & 66,66 & 0,02 & $\mathrm{~V}$ \\
\hline
\end{tabular}

The decrease in the Swedov's viscosity $\eta_{1}$ of the $\mathrm{Zd}$ sample compared to Np correlates with the numbers of the conditional modulus of deformation $E_{\varepsilon}\left(0,28 \cdot 10^{-10}\right.$ vs. $\left.2,57 \cdot 10^{-10} \mathrm{j} / \mathrm{cm}^{3}\right)$ or, accordingly, with a decrease in the forces of molecular interaction and energy the connection of the particles of the dispersed phase.

Table 3. Rheological parameters of cement sludge.

\begin{tabular}{llll}
\hline Mixture code (humidity, wt.\%) & $\begin{array}{l}\text { Conditional dynamically yield } \\
\text { strength } \mathbf{P K}_{\mathbf{2}}, \mathbf{P a}\end{array}$ & $\begin{array}{l}\text { The smallest plastic viscosity } \\
\boldsymbol{\eta}_{\mathbf{m}} \mathbf{x}_{\mathbf{1 0}} \mathbf{1 0}^{-\mathbf{2}}, \mathbf{P a} \cdot \mathbf{c}\end{array}$ & ${\text { Dynamically plasticity } \boldsymbol{\Psi} \cdot \mathbf{1 0}^{4}, \mathbf{c}^{-1}}$ \\
\hline $\mathrm{Np}(37,6)$ & 4,34 & 0,4 & 0,108 \\
$\mathrm{Zd}(37,6)$ & 6,49 & 0,61 & 0,110 \\
\hline
\end{tabular}

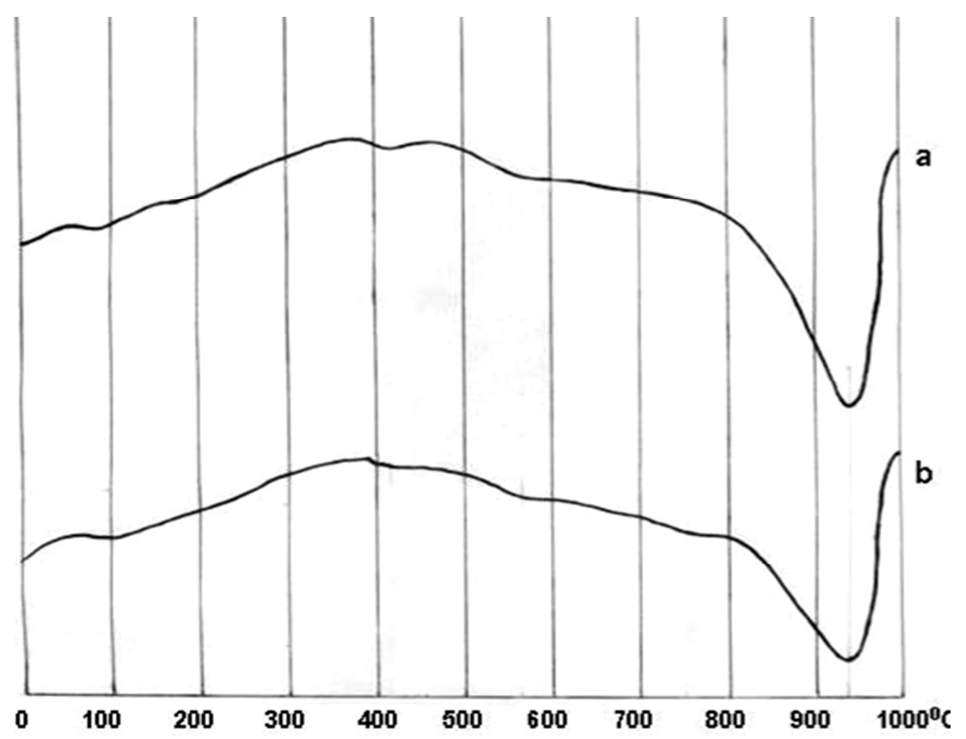

Figure 1. DTA curves of raw mixture $Z d(a)$ and $N p(b)$.

Differences in the composition of industrial raw materials significantly affect the physico - chemical processes that occur during firing. Thus, according to a comprehensive thermal analysis (Figure 1), the sample mixture $\mathrm{Zd}$ in comparison with $\mathrm{Np}$ is characterized by a shift in the parameters of the endothermic effect associated with the destruction of the kaolinite lattice in the region of lower temperatures: begins at 490 vs. $500^{\circ} \mathrm{C}$ and ends at 600 vs. $605^{\circ} \mathrm{C}$ with a maximum at 560 against $570^{\circ} \mathrm{C}$. As for calcite, the temperature characteristics of the endothermic effect in the range of $800-900^{\circ} \mathrm{C}$ are almost the same for $\mathrm{Np}$ and $\mathrm{Zd}$ samples, but in the case of the latter, a larger area of the endoeffect is associated with a correspondingly higher content of calcite.

3a obtained data of X-ray phase analysis, it is obvious (Figures 2, 3) that when increasing the degree of heat treatment to a temperature of $1100^{\circ} \mathrm{C}$ there is a significant decrease in the concentration of crystalline quartz, complete destruction of crystal lattices of calcite and clay rocks, instead due to physicochemical interaction crystallization of neoplasms of calcium silicates, aluminates and calcium aluminoferites is fixed. The $\mathrm{Zd}$ sample differs from $\mathrm{Np}$ by the more intensive formation of mayenite and calcium silicates. 


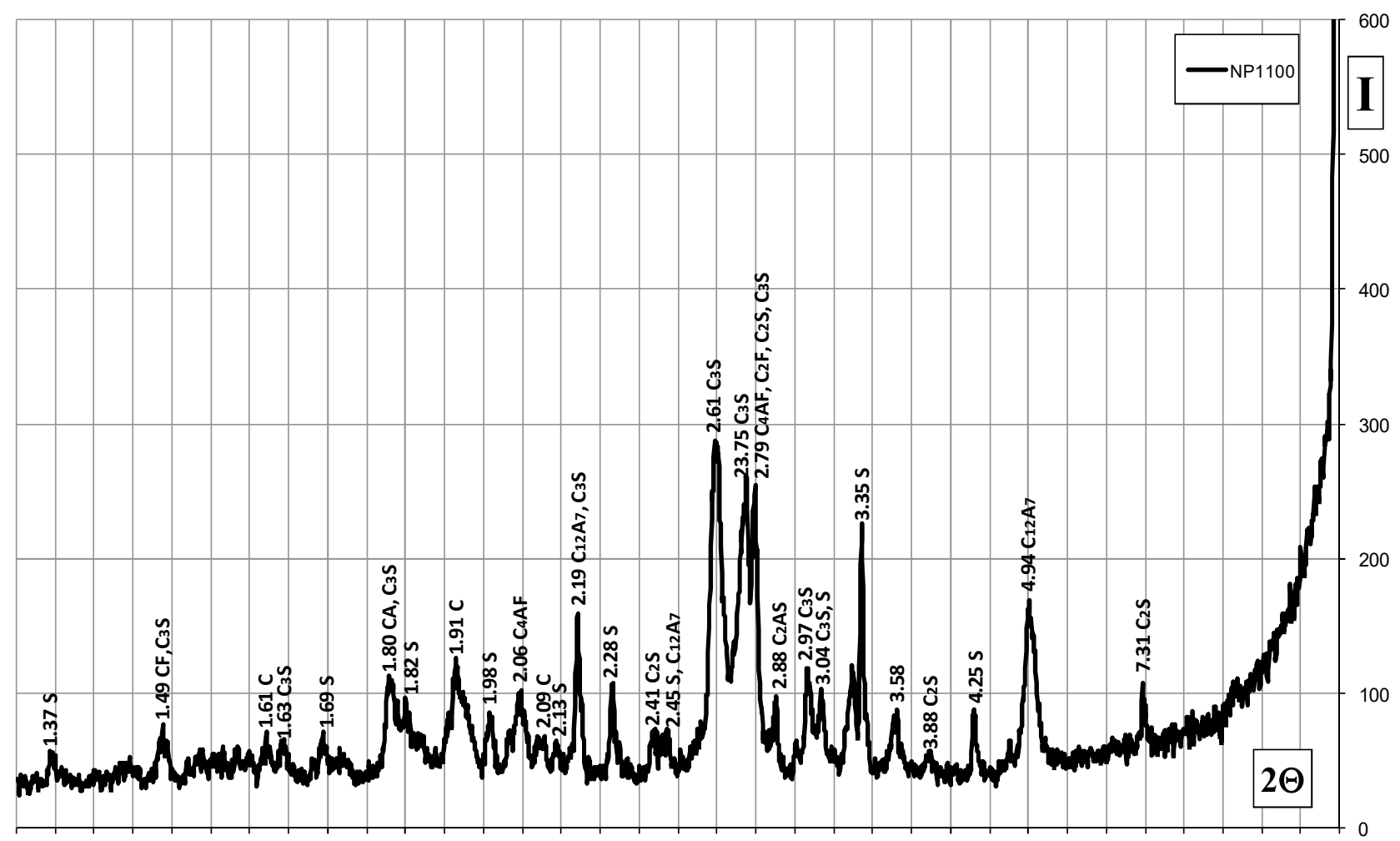

$\begin{array}{lllllllllllllllllllllllllllllllllllllll}70 & 68 & 66 & 64 & 62 & 60 & 58 & 56 & 54 & 52 & 50 & 48 & 46 & 44 & 42 & 40 & 38 & 36 & 34 & 32 & 30 & 28 & 26 & 24 & 22 & 20 & 18 & 16 & 14 & 12 & 10 & 8 & 6 & 4 & 2\end{array}$

Figure 2. X-ray diffraction of clincer $\mathrm{Np}$ after baking at $1100^{\circ} \mathrm{C}$.

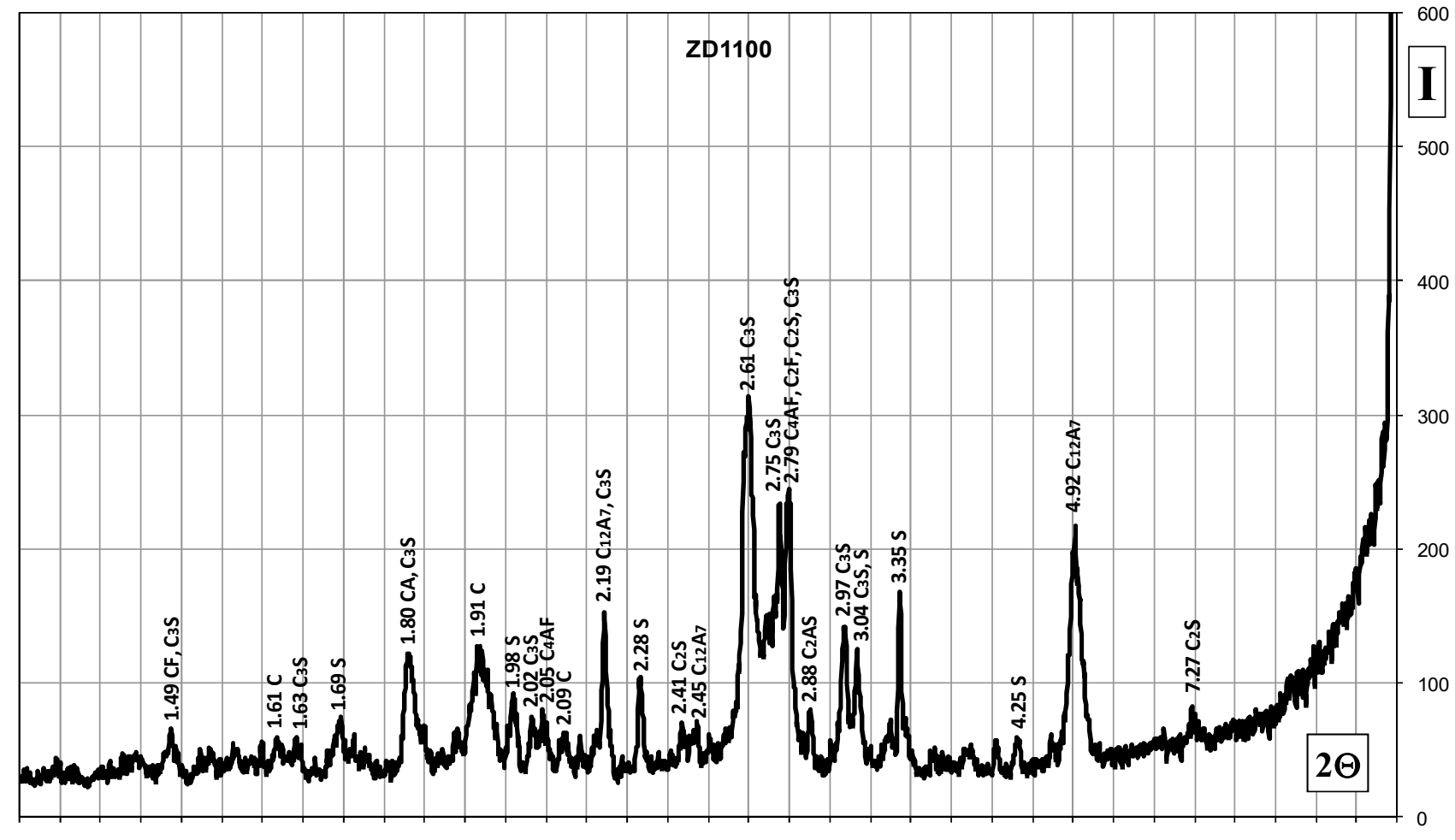

$\begin{array}{lllllllllllllllllllllllllllllllllllll}70 & 68 & 66 & 64 & 62 & 60 & 58 & 56 & 54 & 52 & 50 & 48 & 46 & 44 & 42 & 40 & 38 & 36 & 34 & 32 & 30 & 28 & 26 & 24 & 22 & 20 & 18 & 16 & 14 & 12 & 10 & 8 & 6 & 4 & 2\end{array}$

Figure 3. X-ray diffraction of clincer Zd after baking at $1100^{\circ} \mathrm{C}$.

After firing in a rotary kiln to a maximum temperature of $1450^{\circ} \mathrm{C}$ in clinker, there is a significant increase in the content of calcium silicates, mainly type $\mathrm{C} 3 \mathrm{~S}$, some increase in the concentration of calcium ferrites (Figures 4,5 ). 


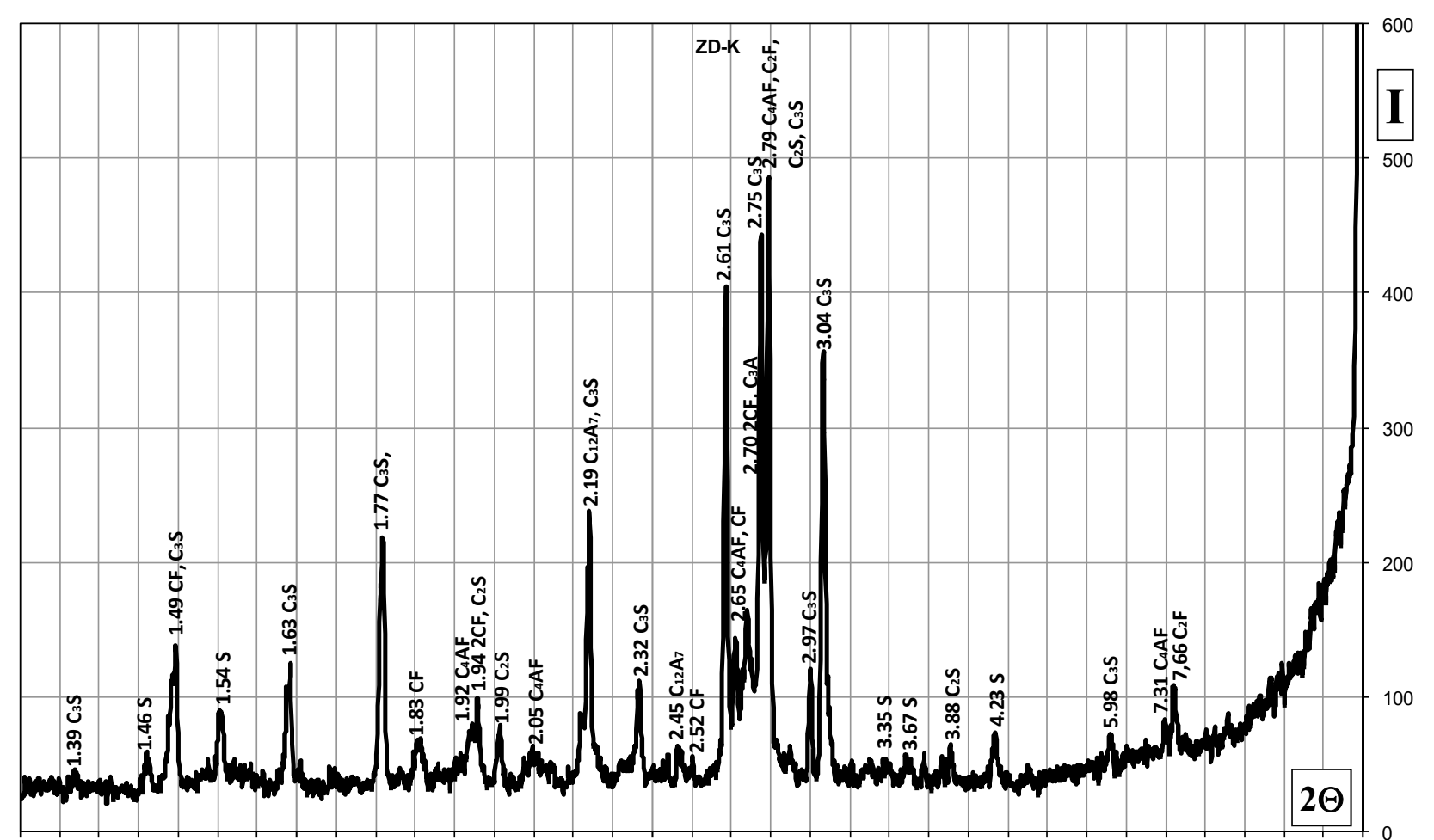

$\begin{array}{llllllllllllllllllllllllllllllllllll}70 & 68 & 66 & 64 & 62 & 60 & 58 & 56 & 54 & 52 & 50 & 48 & 46 & 44 & 42 & 40 & 38 & 36 & 34 & 32 & 30 & 28 & 26 & 24 & 22 & 20 & 18 & 16 & 14 & 12 & 10 & 8 & 6 & 4 & 2\end{array}$

Figure 4. X-ray diffraction of clincer Zd after baking at $1450^{\circ} \mathrm{C}$.

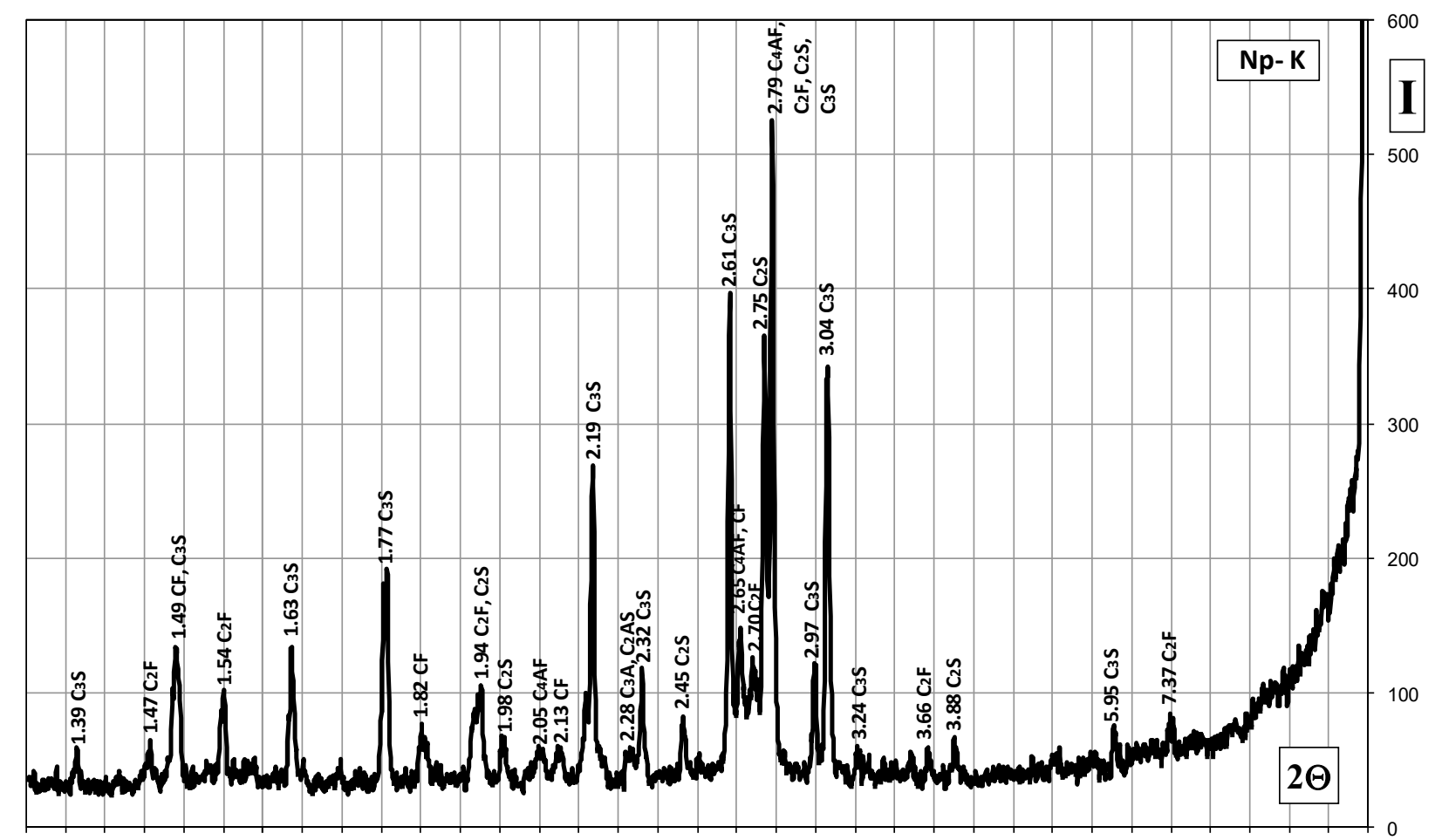

$\begin{array}{lllllllllllllllllllllllllllllllllllll}70 & 68 & 66 & 64 & 62 & 60 & 58 & 56 & 54 & 52 & 50 & 48 & 46 & 44 & 42 & 40 & 38 & 36 & 34 & 32 & 30 & 28 & 26 & 24 & 22 & 20 & 18 & 16 & 14 & 12 & 10 & 8 & 6 & 4 & 2\end{array}$

Figure 5. $X$-ray diffraction of clincer $\mathrm{Np}$ after baking at $1450^{\circ} \mathrm{C}$.

\section{Conclusion}

1. The development of physical and chemical principles of structure formation of dispersed systems in the processes of manufacturing raw materials mixtures, obtaining clinker and its grinding is the basis for further modernization of technology and equipment of Portland cement production. 
2. At the stages of cement production technology disperse systems belong to groups: 2 - sludge in wet and combined production methods, 3 - raw flour in dry method, 1 - finished product, depending on the availability and quantitative ratio of dispersed phase, liquid and gaseous dispersion medium.

3. The chemical and mineralogical composition of the raw material mixture is a common factor in the formation of stages of the technological process of cement production, determining the characteristics of the coagulation structure in wet and combined methods, sintering intensity and the nature of phase transformations during firing and crystallization structure and binder properties.

\section{References}

[1] Runova R. F., Nosovskyy U. L., Dvorkin L. J., Dvorkin O. L. Binders- Kyiv: Osnova, 2012. - 448 p.

[2] Paschenko A. A., Serbin V. P., Starchevskaia O. O. Binders Kyiv: «Vysha shkola», 1995. -437 p.

[3] Ghosh S. N. Adances in Cement Technology: Chemistry, Manufacture and Testing / Taylor \& Francis, 2003. - 828 p.

[4] Nichiporenko S. P., Kruglitsky N. N., Panasevich A. A., Khilko V. V. Physico-chemical mechanics of dispersed minerals. Under the total. ed. Nichiporenko S. P.- Kyiv: Naukova dumka, 1974. - 246 p.

[5] Salnik V. G., Sviderskyy V. A., Chernyak L, P. Physico- chemical mechanics of dispersed structures in building porcelain technology - Kyiv: «Znannia», 2012. - 158 p.

[6] Dorogan N. O., Sviderskyy V. A., Chernyak L. P. White Potrland Cement - Kyiv: «Politechnika», 2018. - 204 p.

[7] Uryev N. B. Highly concentrated dispersed systems and materials - M.: Techpolitgrafcenter, 2018. -407 p.

[8] Budnikov P. P., Ginstling A. M. Reactions in mixtures of solids. - M.: Stroyizdat, 1971.- 488 p.

[9] Richardson J., Taylor H. F. W. Cement Chemistry - London: ICE Publishing; 3 edition, 2020. -600 p.

[10] Harsha Praneeth Pavani, Tezeswi Tadepalli, Ashish Kumar Agrawal. Thermal behaviour of PPC and OPC-53 when exposed to extreme temperatures - Advances in Cement Research, 2020. -32: 8, pp. 358-370.

[11] Kurdowski W. Cement and Concrete Chemistry - Springer Netherlands, 2014. -700 p.

[12] Ludwig H-M, Zhang W. Research review of cement clinker chemistry - Cement and Concrete Research, 2015. - Vol. 78.

[13] Hewlett P., Liska M. Lea's Chemistry of Cement and Concrete - London: Butterworth-Heinemann; 5 edition, 2019. - 896 p.

[14] Gartner E., Sui T. Alternative cement clinkers - Cement and Concrete Research, 2018. - Vol. 114. - pp. 27-39.

[15] Valencia D. E. J., Baena O. J. R. Portland Cement Clinker Formation: High 18. Temperature Equilibria and Phase Composition Prediction. In: The Minerals, Metals \& Materials Society (eds) TMS 2015 144th Annual Meeting \& Exhibition, 2015. - Springer, Cham. - pp. 879-886. 